\title{
Occurrence of Serious Infection in Patients with Rheumatoid Arthritis Treated with Biologics and Denosumab Observed in a Clinical Setting
}

\author{
Arthur N. Lau, Matthew Wong-Pack, Rod Rodjanapiches, George Ioannidis, Sally Wade, \\ Leslie Spangler, Akhila Balasubramanian, Nicola Pannacciulli, Celia J.F. Lin, Patrick Roy-Gayos, \\ William G. Bensen, Robert Bensen, and Jonathan D. Adachi
}

ABSTRACT. Objective. Previous studies combining biologic disease-modifying antirheumatic drugs (bDMARD)
to treat rheumatoid arthritis (RA) have shown an increased risk of infection. However, the risk of
infection with concurrent use of denosumab, a biologic agent for the treatment of osteoporosis, and a
bDMARD remains unclear. Here, we evaluated the incidence of serious and opportunistic infections
in patients treated concurrently with denosumab and a bDMARD and patients treated with a bDMARD
alone.
Methods. A chart review of patients with RA from 2 Canadian rheumatology practices between July
1, 2010, and July 31,2014 , identified 2 groups of patients: those taking denosumab and a bDMARD
concurrently (concurrent group) and those taking only a bDMARD (biologic-alone group). Patients
were followed from the time of initiation of denosumab, or a matched index date for the biologic-alone
group, to the end of the study or loss to followup. Instances of serious or opportunistic infections were
recorded.

Results. A total of 308 patients $(n=102$ for the concurrent group and $n=206$ for the biologic-alone group) were evaluated. Within the concurrent group, 3 serious infection events occurred. Within the biologic-alone group, 4 serious infection events and 1 opportunistic infection event occurred. In both groups, all patients with serious or opportunistic infection recovered, and there were no instances of death during the study period.

Conclusion. This study demonstrated a low occurrence of serious and opportunistic infections in patients with RA taking bDMARD, including patients with concurrent denosumab use. (First Release November 15 2017; J Rheumatol 2018;45;170-6; doi:10.3899/jrheum.161270)

Key Indexing Terms:

RANK LIGAND

OSTEOPOROSIS

DISEASE-MODIFYING ANTIRHEUMATIC DRUGS INFECTION

RHEUMATOID ARTHRITIS

Rheumatoid arthritis (RA) is associated with a number of comorbidities, including osteoporosis, which leads to an increased risk of fractures ${ }^{1,2}$. Many factors contribute to this increased risk of fracture, including a chronic inflammatory state and treatment with glucocorticoids ${ }^{3,4}$. Given the well-recognized risk of bone loss associated with RA,
From the Division of Rheumatology, Department of Medicine, Faculty of Health Sciences, Faculty of Science, and Geriatric Education and Research in Aging Sciences Centre, McMaster University; Charlton Healthcare and St. Joseph's Healthcare Hamilton, Hamilton, Ontario, Canada; Wade Outcomes Research and Consulting, Salt Lake City, Utah; Global Health Economics, Clinical Development, Amgen Inc., Thousand Oaks, California, USA.

Amgen Inc. funded this study. A.N. Lau has received consulting fees, speaking fees, and/or honoraria from Amgen Inc. W.G. Bensen received consulting fees, speaking fees, and/or honoraria from Amgen Inc. J.D. Adachi has received consulting fees, speaking fees, and/or honoraria from Amgen Inc. S. Wade has received consulting fees from Amgen Inc. L. Spangler, A. Balasubramanian, and N. Pannacciulli are employees of Amgen Inc. and have received Amgen Inc. stock and/or stock options. C.J. Lin is a former employee of Amgen Inc. and has received Amgen Inc. and Genentech/Roche stock and/or stock options.

A.N. Lau, MD, Assistant Professor, Division of Rheumatology, McMaster University; M. Wong-Pack, BHSc, Faculty of Health Sciences, McMaster University; R. Rodjanapiches, BHSc, Faculty of Health Sciences, McMaster University; G. Ioannidis, MSc, PhD, GERAS Scientist, Geriatric Education and Research in Aging Sciences Centre and Assistant
Professor (part-time), divisions of Rheumatology and Geriatrics, McMaster University and Hamilton Health Sciences, St. Peter's Hospital; S. Wade, MPH, Consultant, Wade Outcomes Research and Consulting; L. Spangler, VMD, PhD, Senior Manager, Global Health Economics, Amgen Inc.; A. Balasubramanian, MPH, PhD, Observational Research Senior Manager, Center for Observational Research, Amgen Inc.; N. Pannacciulli, MD, PhD, Clinical Research Medical Director, Clinical Development, Amgen Inc.; C.J. Lin, MD, currently Genentech, South San Francisco, California, USA; P. Roy-Gayos, BSc, Faculty of Science, McMaster University; W.G. Bensen, MD, Clinical Professor, Department of Medicine, McMaster University and St.Joseph's Healthcare Hamilton; R. Bensen, MSc, Charlton Healthcare Hamilton and St. Joseph's Healthcare Hamilton; J.D. Adachi, MD, Professor, Department of Medicine, McMaster University and St. Joseph's Healthcare Hamilton. Dr. William G. Bensen died March 15, 2017.

Address correspondence Dr. A.N. Lau, Division of Rheumatology, McMaster University, 501-525 Charlton Ave. East, Hamilton, Ontario L8S 4LB, Canada.E-mail: arthur.lau@medportal.ca Full Release Article. For details see Reprints and Permissions at jrheum.org Accepted for publication August 11, 2017. 
patients with RA are often given pharmacotherapy for osteoporosis. Oral bisphosphonates have long been the mainstay in the treatment of osteoporosis ${ }^{5}$. Denosumab, a novel antiresorptive agent used for the treatment of osteoporosis ${ }^{6,7}$, provides an alternative. Denosumab is a fully human monoclonal antibody that binds to receptor activator of nuclear factor- $x$ B (RANK) ligand (RANKL) and blocks the interaction of RANKL with its receptor on the surface of osteoclasts and osteoclast precursors. This leads to a reduction in osteoclast number and activity, a decrease in bone resorption, an increase in bone mass, and a reduction in vertebral and nonvertebral fracture risk ${ }^{1,8}$.

RANKL is expressed in activated $\mathrm{T}$ and $\mathrm{B}$ lymphocytes and in lymph nodes; therefore, there is a theoretical possibility that denosumab may increase the risk of infections due to inhibition of the RANK pathway ${ }^{9,10}$. In the pivotal FREEDOM study ${ }^{8}$, which assessed the use of denosumab in postmenopausal women with osteoporosis, there was no difference in the overall rates of infection between the denosumab and placebo groups, even though an imbalance in serious skin infections [associated with intravenous (IV) antibiotics or hospitalization] was observed. In addition, earlier studies showed no significant changes in white blood cell counts, overall lymphocyte counts, or lymphocyte subset counts in subjects receiving denosumab, and animal models suggest that immune function remains intact in the presence of RANKL inhibition ${ }^{1,11}$.

Nonetheless, given the possibility of increased risk of infection among patients treated with denosumab, there is an interest in understanding the safety of using denosumab to treat osteoporosis in patients being treated for RA with other biologic drugs. Previous studies have suggested that exposure to multiple biologic agents, each carrying an independent elevated risk of infection, may be associated with an even higher risk of infection. Two small studies found that the combination of a tumor necrosis factor- $\alpha$ (TNF- $\alpha$ ) inhibitor with a second biologic agent, which used another mechanism of action (i.e., anakinra and abatacept, respectively), resulted in higher rates of infection ${ }^{12,13}$. Given these concerns, the current American College of Rheumatology (ACR) guidelines ${ }^{14}$ recommend against using biologics in combination for the treatment of RA.

Previous studies that have examined the use of denosumab in combination with other biologic drugs have found no evidence of increased infection risk associated with concurrent exposure $8,15,16$. In our present study, we used electronic medical records (EMR) and patient charts from 2 academic rheumatology practices in Canada to describe the occurrence of serious infections in 2 groups of patients with RA, specifically, patients with osteoporosis treated concurrently with denosumab and a biologic disease-modifying antirheumatic drug (bDMARD) and patients treated with a bDMARD alone.

\section{MATERIALS AND METHODS}

Study cohort. The study population consisted of adult patients with RA being treated with a bDMARD, including a group of patients with moderate to high risk for fracture (as determined by the clinician), who were treated concurrently with denosumab and a bDMARD. The study population was derived from patients from 2 academic rheumatology practices located in Hamilton, Ontario, Canada, between July 1, 2010, and July 31, 2014. The July 2010 inception date was selected because it coincides with the date Health Canada approved the use of denosumab for the treatment of postmenopausal women with osteoporosis at high risk for fracture. Since 2010 , the medical records from these rheumatology practices included about 3000 patients taking bDMARD therapy. The diagnosis of RA was based on the clinical judgment of the treating rheumatologist, and this was identified for our study using both clinic notes and International Classification of Diseases codes used for billing purposes. Therefore the ACR classification criteria for RA may not have been applied to all patients.

Information regarding exposure to medications of interest, including start and stop dates, was obtained from the database of the Pharmaca Health Inc. pharmacy, which serves all the patients seen at the rheumatology practices in our study. Other data for the study, including determination of eligibility criteria, patient clinical characteristics, and outcomes, were obtained from review of EMR from the clinics, clinic visit notes, and linked patient data from the pharmacy database. Study approval was obtained from the institutional research ethics board (REB tracking number 14-12-003).

Eligible patients satisfied the following inclusion criteria: $\geq 18$ years old with an RA diagnosis; registered in the Hamilton rheumatology medical practices $\geq 3$ months before and 3 months after the index date as defined below; and received $\geq 1$ injection, or infusion, or filled a prescription for a biologic medication for RA with Pharmaca Health Inc. during the study period. Patients were excluded if they had any of the following: evidence of human immunodeficiency virus or AIDS, treatment for any prevalent cancers, immunosuppressive therapies for conditions other than RA (i.e., organ transplant), or evidence of a nursing home stay.

Initial patient selection focused on the identification of patients who were concurrently exposed to biologic RA medication and denosumab (the concurrent group). Patients in the concurrent group were required to have moderate to high risk of fracture and have received $\geq 1$ injection of denosumab while taking a bDMARD in addition to meeting the other eligibility criteria. Conversely, patients receiving only a bDMARD (the biologic-alone group) never received denosumab during the study period. The date of the first denosumab injection while receiving biologic therapy marked the "index date" and served as the start of patient followup for the concurrent group. This served as the index date even if the patient had been treated with a bDMARD before starting denosumab. The index date was required to have occurred between July 1, 2010, and July 31, 2014. Patients in the biologic-alone group were assigned index dates at random to provide comparable followup time to the concurrent group. Patient covariates were collected closest to the index date within 6 months before and/or after the index date. Hospitalizations were monitored 12 months prior to the index date until the end of the study.

The patients in the concurrent group were matched 1:2 to patients receiving solely a bDMARD, and results for the biologic-alone group are presented separately. The index dates for the concurrent groups were stratified based on the year each patient began concurrent therapy. An average index date was obtained for each year (e.g., 2010, 2011, 2012) to provide comparable followup for the biologic-alone group. The biologic-alone patients were randomly selected from the population of patients with RA derived from the 2 rheumatology practices and were then randomly assigned 1 of the average index dates, which also served as their starting point for monitoring patient followup. Patients in the biologic-alone group were required to have initiated biologic therapy prior to their index date, but were not required to have a moderate to high risk for fracture for study inclusion. As with the concurrent group, patient covariates were collected closest to the index date within 6 months before and/or after the index date. Hospitalizations were monitored 12 months prior to the index date until the end of the study.

In both the concurrent and biologic-alone groups, followup began at the index date and continued until the end of the study (July 31,2014) or loss to

Personal non-commercial use only. The Journal of Rheumatology Copyright (C) 2018. All rights reserved. 
followup from the respective Hamilton rheumatology medical practice, whichever came first. Reasons for loss to followup included patient relocation, noncompliance to medication, patient discontinuation of medication, or death. Drug discontinuation was determined using the pharmacy billing records to ensure that the patient filled his or her prescription. The assumption was made that patients were compliant with their medications if they had filled their prescription, unless there was documentation in a patient's medical records suggesting potential noncompliance. Loss to followup was determined on the basis of specific evidence in the medical records to indicate that any of the criteria for loss to followup had been met; in the absence of such specific evidence, patients were assumed to be in followup and exposed to a bDMARD and denosumab, as relevant.

Exposures. Exposure to a bDMARD was defined as treatment with 1 of the following therapies during the followup period: a TNF- $\alpha$ inhibitor (adalimumab, certolizumab, etanercept, infliximab, or golimumab) or a biologic using another mechanism of action (abatacept, anakinra, rituximab, tocilizumab, or ustekinumab). Exposure to denosumab was defined as receiving $\geq 1$ dose of denosumab (60 mg once every 6 mos) during the study period. Pharmaca Health Inc. provided documentation for bDMARD therapy and denosumab injections, including the date administered, dosage, quantity, and any patient reaction(s) to the medications. All data on the medication fill note were transmitted electronically from the pharmacy to the rheumatology practices. The medication history was further confirmed through an examination of the clinic EMR for each patient. Patients in the concurrent and biologic-alone groups at the index date were assumed to have continued their medications up until the end of the study period (July 31,2014) or until loss to followup, whichever came first.

Outcomes assessment. The primary outcome of interest was the occurrence of serious infections during the followup period. A serious infection was defined as either hospitalization for at least $24 \mathrm{~h}$ associated with a primary diagnosis of infection, or an emergency room visit associated with a primary diagnosis of infection and treatment with at least 1 course of IV antibiotics. We reported the number of patients with at least 1 serious infection and the total number of serious infection events during the followup period. The secondary outcome of interest was the occurrence of opportunistic infection, including infection with the following pathogens: Mycobacterium tuberculosis, Mycobacterium avium, cytomegalovirus, varicella zoster virus, herpes simplex virus, Cryptosporidium, Toxoplasma gondii, Cryptococcus neoformans, Pneumocystis carinii, Histoplasma capsulatum, or other invasive fungi.

Outcomes of interest were identified by reviewing hospital discharge summaries in the clinic EMR for all included patients, in addition to reviewing clinic visit notes and any pharmacy queries during the followup period. To ensure events of interest were identified, patients were routinely asked at each clinic visit and by the pharmacy at the time of medication fill if they had been hospitalized. Any discrepancies between patient report and hospital or pharmacy notifications were investigated.

All potential events identified were independently reviewed by 2 internal adjudicators of the outcomes (ANL and JDA). When a disagreement existed between the 2 outcomes adjudicators, a third adjudicator (WGB) was consulted to resolve the disagreement.

Covariates. A number of covariates related to patient demographic, behavioral, and clinical characteristics, as well as details on diagnostic laboratory tests and medication use, were collected at baseline and assessed within 6 months prior to each patient's index date. Baseline disease activity was collected for both groups, but the analysis did not adjust for differences in baseline disease activity. The information was derived from the rheumatology clinics' EMR databases, clinic visit notes, and Pharmaca Health Inc. records.

Statistical analysis. The observed frequency of infection was recorded for the concurrent and biologic-alone groups. For both groups, descriptive statistics are presented as means (SD) for continuous and counts (percentage) for categorical variables. The risk of serious infection outcomes was evaluated in terms of the incidence rate per 100 patient-years $(95 \% \mathrm{CI}$ ), which was calculated as the total number of infection events divided by the summation of patient-time at risk, where time at risk was censored at the end of the study or end of available followup. The rate of serious infection was separately evaluated in patients using methotrexate (MTX) and prednisone, given that both these medications may increase the rate of infection in this patient population and are potential confounding variables. Differences between incident rates were calculated using MedCalc Statistical Software version 14.12.0 (MedCalc Statistical Software BVBA) and descriptive statistics were summarized using SAS version 9.3 for Windows (SAS Institute Inc.).

\section{RESULTS}

We identified 191 patients who had a history of being treated with bDMARD therapies and denosumab. After excluding patients based on technical limitations (e.g., no patient data available in the clinic EMR) and applying the inclusion and exclusion criteria, 102 patients were identified for the concurrent group (Figure 1). After matching patients based on the derived index dates for patients in the concurrent group, 206 patients were identified for the biologic-alone group.

Participant characteristics for both groups are provided in Table 1. Compared with patients in the biologic-alone group, concurrently exposed patients were more likely to be female and of older age. Concurrently exposed patients were also more likely to have a bone mineral density $\mathrm{T}$ score in the osteoporotic range and a history of fracture. Patients in the biologic-alone group had a higher frequency of cardiovascular disease, chronic obstructive pulmonary disease (COPD), and diabetes.

Descriptive statistics pertaining to biologic and conventional DMARD use are provided in Table 2. Patients in the biologic-alone group had a higher frequency of MTX use and those in the concurrent group had a higher frequency of prednisone use. Rates of infection are provided in Table 3. Regarding the primary outcome, there were 3 serious infection events among the 102 patients in the concurrent group, and 4 serious infection events and 1 opportunistic infection event among the 206 patients in the biologic-alone group. The rates of serious or opportunistic infections were 1.22 per 100 patient-years (95\% CI $0.25-3.56)$ in the concurrent group and 0.98 per 100 patient-years $(95 \% \mathrm{CI}$ $0.32-2.29$ ) in the biologic-alone group (rate difference 0.24 , $\mathrm{p}=0.77)$. The most common type of infection was pneumonia $(n=6)$.

A subgroup analysis was performed examining rates of serious infection associated with MTX and prednisone use. Event rate per 100 patient-years was 0.83 (95\% CI 0.02-4.60) in the concurrent group and $0.30(95 \% \mathrm{CI} 0.00-1.67)$ in the biologics-alone group among MTX users (rate difference 0.53 , $\mathrm{p}=0.46), 5.56$ (95\% CI 1.15-16.24) in the concurrent group and 3.30 (95\% CI 0.08-18.57) in the biologics-alone group for prednisone users (rate difference 2.22, $\mathrm{p}=0.65$ ), and 4.55 (95\% CI 0.12-25.33) in the concurrent group and 0.00 (95\% CI 0.00-16.77) in the biologics-alone group for MTX and prednisone users combined (rate difference 4.55, $\mathrm{p}=0.32$ ).

Personal non-commercial use only. The Journal of Rheumatology Copyright @ 2018. All rights reserved 


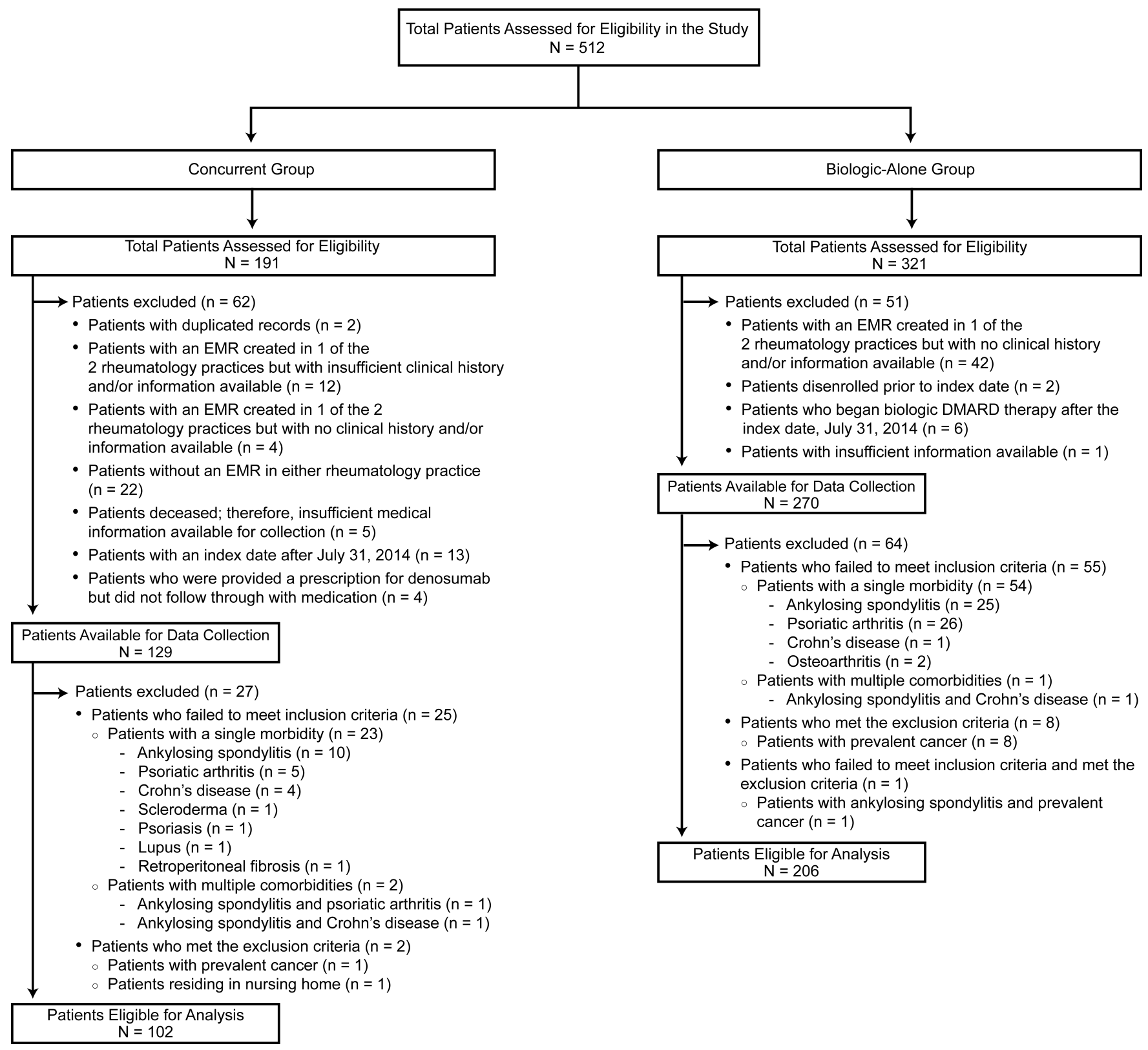

Figure 1. Flowchart of patient eligibility. DMARD: disease-modifying antirheumatic drug; EMR: electronic medical record.

\section{DISCUSSION}

Our present study showed that, in a real-world setting, the occurrence of serious infections was low in patients with RA treated concurrently with a bDMARD and denosumab, and in patients treated with a bDMARD alone. These results are consistent with those from previous retrospective cohort studies assessing infection rates in patients with RA treated concurrently with denosumab and a bDMARD ${ }^{17,18}$.

A retrospective cohort study using the US Medicare administrative claims database ${ }^{19}$ analyzed data from 5814 patients with RA to compare the rates of hospitalized infection in patients receiving denosumab concurrently with a bDMARD with those of patients receiving zoledronic acid concurrently with a bDMARD. The investigators specified an a priori noninferiority margin to compare the 2 groups and found that the rate of hospitalized infection was not greater among patients using denosumab [14.9 per 100 patient-yrs (95\% CI 12.2-18.1)] compared with those using zoledronic acid [13.9 per 100 patient-yrs (95\% CI 12.5-15.4) ${ }^{19}$. It is important to note that in that study, patients within both groups may have experienced more than 1 infection in a single hospitalization, and in contrast to our study, patients may have had repeated infections. Further, the population in the study by Curtis, et al ${ }^{19}$ had higher percentages of comor-

Personal non-commercial use only. The Journal of Rheumatology Copyright @ $\odot 2018$. All rights reserved 
Table 1. Participant characteristics. Data recorded within \pm 6 months of the index date. Data are means (SD) unless otherwise noted.

\begin{tabular}{|c|c|c|c|c|}
\hline \multirow{2}{*}{$\begin{array}{l}\text { Characteristics } \\
\text { Women, n (\%) }\end{array}$} & \multicolumn{2}{|c|}{$\begin{aligned} \text { Concurrent, } \mathrm{n} & =102 \\
& \text { Missing Data, } \mathrm{n}(\%)\end{aligned}$} & \multicolumn{2}{|c|}{$\begin{array}{l}\text { Biologic Alone, } \mathrm{n}=206 \\
\text { Missing Data, } \mathrm{n}(\%)\end{array}$} \\
\hline & $90(88.2)$ & $0(0)$ & $158(76.7)$ & $0(0)$ \\
\hline Followup time from index date, yrs & $2.4(1.2)$ & $0(0)$ & $2.5(1.3)$ & $0(0)$ \\
\hline Duration on denosumab, yrs & $2.4(1.2)$ & $0(0)$ & NA & NA \\
\hline Body mass index, $\mathrm{kg} / \mathrm{m}^{2}$ & $27.3(5.5)$ & $2(2.0)$ & $31.2(6.3)$ & $38(18.4)$ \\
\hline Cardiovascular disease, $\mathrm{n}(\%)$ & $7(6.9)$ & $0(0)$ & $19(9.2)$ & $0(0)$ \\
\hline Chronic kidney disease, $\mathrm{n}(\%)$ & $1(1.0)$ & $0(0)$ & $4(1.9)$ & $0(0)$ \\
\hline Chronic obstructive pulmonary disease, $\mathrm{n}(\%)$ & $4(3.9)$ & $0(0)$ & $16(7.8)$ & $0(0)$ \\
\hline Diabetes, $\mathrm{n}(\%)$ & $8(7.8)$ & $0(0)$ & $25(12.1)$ & $0(0)$ \\
\hline Liver disease, $\mathrm{n}(\%)$ & $1(1.0)$ & $0(0)$ & $1(0.5)$ & $0(0)$ \\
\hline Smoking status, $\mathrm{n}(\%)$ & & 1 & & 13 \\
\hline $\mathrm{C}$-reactive protein, $\mathrm{mg} / \mathrm{l}$ & $4.6(6.8)$ & $23(22.5)$ & $4.5(8.0)$ & $38(18.4)$ \\
\hline $\mathrm{ESR}, \mathrm{mm} / \mathrm{h}$ & $19.0(17.0)$ & $24(24.5)$ & $17.2(15.2)$ & $38(18.4)$ \\
\hline Swollen joint count & $4.7(4.2)$ & $37(36.3)$ & $4.8(5.0)$ & $38(18.4)$ \\
\hline Tender joint count & $8.2(10.1)$ & $44(43.1)$ & $6.6(7.0)$ & $45(21.8)$ \\
\hline
\end{tabular}

Summary statistics and percentages are calculated based on non-missing observations. Percentages for missing data are calculated based on total population for each group ( $\mathrm{n}=102$, concurrent group; $\mathrm{n}=206$, biologic-alone group). BMD: bone mineral density; NA: not applicable; ESR: erythrocyte sedimentation rate.

Table 2. DMARD composition within the concurrent and biologic-alone groups. Data are shown as n (\%) of patients, unless stated otherwise.

\begin{tabular}{lcc}
\hline Medication & $\begin{array}{c}\text { Concurrent, } \\
\mathrm{n}=102\end{array}$ & $\begin{array}{c}\text { Biologic Alone, } \\
\mathrm{n}=206\end{array}$ \\
\hline Biologic DMARD & & \\
Anti-TNF & $75(73.5)$ & $146(70.9)$ \\
Adalimumab & $9(8.8)$ & $18(8.7)$ \\
Certolizumab & $8(7.8)$ & $8(3.4)$ \\
Etanercept & $24(23.5)$ & $56(27.2)$ \\
Golimumab & $20(19.6)$ & $22(10.7)$ \\
Infliximab & $14(13.7)$ & $42(20.4)$ \\
Other mechanisms & $27(26.5)$ & $60(29.1)$ \\
Abatacept & $14(13.7)$ & $27(13.1)$ \\
Anakinra & $0(0)$ & $0(0)$ \\
Rituximab & $3(2.9)$ & $7(3.4)$ \\
Tocilizumab & $9(8.8)$ & $25(12.1)$ \\
Ustekinumab & $1(1.0)$ & $1(0.5)$ \\
Conventional DMARD* & $81(79.4)$ & $190(92.2)$ \\
Hydroxychloroquine & $11(5.3)$ & $18(8.7)$ \\
Leflunomide & $20(19.6)$ & $42(20.4)$ \\
Methotrexate & $50(49.0)$ & $130(63.4)$ \\
Mean (SD) dose, mg/week & $15.0(5.6)$ & $15.6(4.8)$ \\
Prednisone & $21(20.6)$ & $15(7.4)$ \\
Mean (SD) dose, mg/week & $7.9(7.6)$ & $7.6(4.1)$ \\
\hline
\end{tabular}

*Other medications included in the analysis were minocycline, sulfasalazine, tofacitinib, azathioprine, cyclophosphamide, and mycophenolate mofetil. For both groups, patients were not taking these medications during the study period. DMARD: disease-modifying antirheumatic drug; TNF: tumor necrosis factor. bidities (e.g., diabetes and COPD) compared with our study population. Finally, over 50\% of patients within both exposure groups in the study population in Curtis, et $a l^{19}$ used infliximab, which has been shown to result in a higher risk of infection compared with other bDMARD 20,21 . In comparison, our study population had a balanced use of bDMARD among patients in both the concurrent and biologic-alone groups. While the results of Curtis, et al ${ }^{19}$ are in agreement with our finding that there was no observed increased risk of hospitalized infection among patients treated concurrently with a bDMARD and denosumab, the above combined factors may have contributed to a greater incidence rate per 100 patient-years in their study compared with our findings.

Another study reported a higher rate of serious infections in 10 patients treated concurrently with denosumab and a bDMARD compared with rates in patients taking either denosumab $(n=159)$ or a bDMARD $(n=193)$ alone ${ }^{22}$. Interpretation of this result, however, is limited by the small number of concurrent users as well as the minimal information available on the patient populations including covariates and risk factors, duration of followup, and the time at risk in the different treatment groups. Further, the authors did not adjust their analyses for age, which is a known risk factor for infection. A previous Canadian prospective cohort study (RHUMDATA) of patients with RA found an increase in the infection rate in patients treated with denosumab alone 
Table 3. Incidence of serious and opportunistic infections within the concurrent and biologic-alone groups.

\begin{tabular}{|c|c|c|c|c|}
\hline \multirow[b]{2}{*}{ Event Category Type } & \multicolumn{2}{|c|}{ Concurrent, $\mathrm{n}=102$} & \multicolumn{2}{|c|}{ Biologic Alone, $\mathrm{n}=206$} \\
\hline & $\begin{array}{l}\text { Event No./Total } \\
\text { No. Patient-Yrs }\end{array}$ & $\begin{array}{c}\text { Events per } 100 \\
\text { Patient-Yrs }(95 \% \mathrm{CI})\end{array}$ & $\begin{array}{l}\text { Event No./Total } \\
\text { No. Patient-Yrs }\end{array}$ & $\begin{array}{c}\text { Events per } 100 \\
\text { Patient-Yrs }(95 \% \mathrm{CI})\end{array}$ \\
\hline \multicolumn{5}{|l|}{ Serious infection requiring hospitalization } \\
\hline Pneumonia & $2 / 246$ & $0.81(0.10-2.94)$ & $2 / 509$ & $0.39(0.05-1.42)$ \\
\hline Bronchitis & - & - & $1 / 509$ & $0.20(0.01-1.09)$ \\
\hline \multicolumn{5}{|c|}{ Serious infection requiring ER visit and IV antibiotics } \\
\hline Pneumonia & $1 / 246$ & $0.41(0.01-2.26)$ & $1 / 509$ & $0.20(0.01-1.09)$ \\
\hline \multicolumn{5}{|l|}{ Opportunistic infection requiring hospitalization } \\
\hline Pleural Mycobacterium avium complex & - & - & $1 / 509$ & $0.20(0.01-1.09)$ \\
\hline Serious infections & $3 / 246$ & $1.22(0.25-3.56)$ & $4 / 509$ & $0.79(0.21-2.01)$ \\
\hline Serious or opportunistic infections (total) & $3 / 246$ & $1.22(0.25-3.56)$ & $5 / 509$ & $0.98(0.32-2.29)$ \\
\hline
\end{tabular}

ER: emergency room; IV: intravenous.

(25.0 per 100 patient-yrs) versus those treated with denosumab in addition to a bDMARD (15.7 per 100 patient-yrs $)^{23}$. However, the sample size in that study was also limited $(n=20$ patients in the combination group; $n=43$ in the denosumab-alone group), and no adjustment was made for potential confounding factors.

Access to detailed clinical information is a strength of our study, which provides a unique evaluation of a cohort of patients with RA in a real-world clinical practice setting. Previous studies have used large administrative databases or RA registries that provide large sample sizes, but often do not provide enough information regarding potential events of interest to confirm the occurrence and severity of such events. In our study, the patients' full medical records were used to gather details surrounding potential events of interest. Further, patients taking a bDMARD were routinely asked about recent infections, hospitalizations, and use of antibiotics at each clinic visit, which maximized the total number of events identified. In addition, having 2 designated adjudicators of outcomes allowed for consistency and reproducibility of the adjudication of outcomes of interest.

The results of our study should be interpreted in light of particular limitations. First, the relatively small sample size and short followup duration may have contributed to the low number of events observed in both groups. Because of our limited sample size, the study was underpowered to detect differences between groups, and the interpretation of nonsignificant results should be viewed with caution. No adjustment was made for any observed imbalances in potential confounders, such as age and comorbidities, between the groups. A history of serious infections, which could be an important prognostic factor, was not uniformly available and hence not assessed. Additionally, we did not have information on the duration of prior exposure to biologics or denosumab, both of which might also influence risk of serious infection. We acknowledge that there are differences in missing data such as fractures and BMD in the biologics alone group. This may well explain the lack of osteoporosis treatment in this group. However, our findings suggest that the incidence of serious infections was low in both groups. The clinics that contributed patient data to our study are highly vigilant regarding vaccination protocols and counseling patients to stop their bDMARD in response to impending signs of infection; therefore, the observed rates of infection may have been lower than those in other clinic populations with different practice standards. Further, as a result of such proactive patient monitoring, infections occurring in this patient population may have been less likely to require hospital admission or IV antibiotics in the emergency room, thereby lowering the number of serious infections observed. Finally, event rates may have been underreported, especially given the definition of a serious infection in our study. This is a general limitation to retrospective studies in general, and is also applicable to our study.

Results from our study suggest that few patients with RA concurrently treated with a bDMARD and denosumab had serious infections or opportunistic infections. The small number of infections observed is consistent with that reported in previous cohort studies and provides additional evidence of the safety of concurrent treatment with denosumab and a bDMARD. Future studies using larger cohorts could shed further light on this important question.

\section{ACKNOWLEDGMENT}

Lisa A. Humphries, $\mathrm{PhD}$, of Amgen Inc. and Martha Mutomba (on behalf of Amgen Inc.) provided editing, formatting, and submission support.

\section{REFERENCES}

1. Bone HG, Bolognese MA, Yuen CK, Kendler DL, Wang H, Liu Y, et al. Effects of denosumab on bone mineral density and bone turnover in postmenopausal women. J Clin Endocrinol Metab 2008;93:2149-57.

2. Orstavik RE, Haugeberg G, Mowinckel P, Hoiseth A, Uhlig T, Falch JA, et al. Vertebral deformities in rheumatoid arthritis: a comparison with population-based controls. Arch Intern Med 2004;164:420-5.

3. Baqai T, Jawad ASM. Bone changes in patients with inflammatory arthritis treated with biological therapies: a clinical perspective. Immunol Endocr Metab Agents Med Chem 2008;8:207-21.

Personal non-commercial use only. The Journal of Rheumatology Copyright (C) 2018. All rights reserved. 
4. van Staa TP, Geusens P, Bijlsma JW, Leufkens HG, Cooper C. Clinical assessment of the long-term risk of fracture in patients with rheumatoid arthritis. Arthritis Rheum 2006;54:3104-12.

5. Papaioannou A, Morin S, Cheung AM, Atkinson S, Brown JP, Feldman S, et al. 2010 clinical practice guidelines for the diagnosis and management of osteoporosis in Canada: summary. Can Med Assoc J 2010;182:1864-73.

6. Prolia (denosumab) prescribing information. Amgen; 2017. [Internet. Accessed October 2, 2017.] Available from: http://pi.amgen.com/ /media/amgen/repositorysites/ pi-amgen-com/prolia/prolia_pi.pdf

7. Prolia (denosumab) EU summary of product characteristics. Amgen; 2017. [Internet. Accessed October 2, 2017.] Available from: www.ema.europa.eu/ema/index.jsp?curl=pages/medicines/human/ medicines/001120/human_med_001324.jsp\&mid=WC0b01ac05800 $1 \mathrm{~d} 124$

8. Cummings SR, San Martin J, McClung MR, Siris ES, Eastell R, Reid IR, et al. Denosumab for prevention of fractures in postmenopausal women with osteoporosis. N Engl J Med 2009;361:756-65.

9. Dore RK. The RANKL pathway and denosumab. Rheum Dis Clin North Am 2011;37:433-52, vi-vii.

10. Watts NB, Roux C, Modlin JF, Brown JP, Daniels A, Jackson S, et al. Infections in postmenopausal women with osteoporosis treated with denosumab or placebo: coincidence or causal association? Osteoporos Int 2012;23:327-37.

11. Bekker PJ, Holloway DL, Rasmussen AS, Murphy R, Martin SW, Leese PT, et al. A single-dose placebo-controlled study of AMG 162 , a fully human monoclonal antibody to RANKL, in postmenopausal women. J Bone Miner Res 2004;19:1059-66.

12. Genovese MC, Cohen S, Moreland L, Lium D, Robbins S, Newmark R, et al. Combination therapy with etanercept and anakinra in the treatment of patients with rheumatoid arthritis who have been treated unsuccessfully with methotrexate. Arthritis Rheum 2004;50:1412-9.

13. Weinblatt M, Schiff M, Goldman A, Kremer J, Luggen M, Li T, et al. Selective costimulation modulation using abatacept in patients with active rheumatoid arthritis while receiving etanercept: a randomised clinical trial. Ann Rheum Dis 2007;66:228-34.

14. Singh JA, Saag KG, Bridges SL Jr., Akl EA, Bannuru RR, Sullivan MC, et al. 2015 American College of Rheumatology guideline for the treatment of rheumatoid arthritis. Arthritis Rheumatol 2016;68:1-26.
15. Orwoll E, Teglbjaerg CS, Langdahl BL, Chapurlat R, Czerwinski E, Kendler DL, et al. A randomized, placebo-controlled study of the effects of denosumab for the treatment of men with low bone mineral density. J Clin Endocrinol Metab 2012;97:3161-9.

16. Roux C, Hofbauer LC, Ho PR, Wark JD, Zillikens MC Fahrleitner-Pammer A, et al. Denosumab compared with risedronate in postmenopausal women suboptimally adherent to alendronate therapy: efficacy and safety results from a randomized open-label study. Bone 2014;58:48-54.

17. Bray V, Bagley A, West S, Etzel C, Kremer J, Kolfenbach J. Infection risk among patients receiving concurrent denosumab and biologic or non-biologic DMARD therapy: An analysis of the Consortium of Rheumatology Researchers of North America (CORRONA) registry. Arthritis Rheum 2013;65 Suppl 10:S215.

18. Prabhakaran S, Pritchard C. Comparison of infection rates in patients receiving denosumab, denosumab and biologics, and biologics alone in a suburban rheumatology clinic [abstract]. Arthritis Rheumatol 2014;66 Suppl 10:S409.

19. Curtis JR, Xie F, Yun H, Saag KG, Chen L, Delzell E. Risk of hospitalized infection among rheumatoid arthritis patients concurrently treated with a biologic agent and denosumab. Arthritis Rheum 2015;67:1456-64.

20. Atzeni F, Sarzi-Puttini P, Botsios C, Carletto A, Cipriani P, Favalli $\mathrm{EG}$, et al. Long-term anti-TNF therapy and the risk of serious infections in a cohort of patients with rheumatoid arthritis: comparison of adalimumab, etanercept and infliximab in the GISEA registry. Autoimmun Rev 2012;12:225-9.

21. van Dartel SA, Fransen J, Kievit W, Flendrie M, den Broeder AA, Visser H, et al. Difference in the risk of serious infections in patient with rheumatoid arthritis treated with adalimumab, infliximab and etanercept: results from the Dutch Rheumatoid Arthritis Monitoring (DREAM) registry. Ann Rheum Dis 2013;72:895-900.

22. Parody I, Arias-Urdaneta L, Garcia Alemany R, Sesin C. Combination therapy with denosumab and biologic DMARD associated with higher risk of serious infections compared to denosumab alone and biologic DMARD alone [abstract]. Arthritis Rheumatol 2015;67 Suppl 10:3171.

23. Haraoui B, Choquette D, Adjo'o Zo'o A, Coupal L. Denosumab, with and without biologic therapy and the risk of infection in patients with rheumatoid arthritis. Ann Rheum Dis 2015;74 Suppl 2:243-4. 